Rapid report

\title{
The pitfalls of in vivo imaging techniques: evidence for cellular damage caused by synchrotron X-ray computed micro-tomography
}

Author for correspondence:

Andrea Nardini

Tel: +390405583890

Email: nardini@units.it

Received: 2 June 2018

Accepted: 4 July 2018

\section{Francesco Petruzzellis ${ }^{1}$, Chiara Pagliarani ${ }^{2,3}$, Tadeja Savi ${ }^{1,4}$, Adriano Losso ${ }^{5}$, Silvia Cavalletto ${ }^{3}$, Giuliana Tromba ${ }^{6}$, Christian Dullin ${ }^{6,7,8}$, Andreas Bär ${ }^{5}$, Andrea Ganthaler ${ }^{5}$, Andrea Miotto ${ }^{1}$, Stefan Mayr ${ }^{5}$, Maciej A. Zwieniecki', Andrea Nardini ${ }^{1}$ and Francesca Secchi ${ }^{3}$}

\author{
${ }^{1}$ Dipartimento di Scienze della Vita, Università di Trieste, Via L. Giorgieri 10, 34127 Trieste, Italy; ${ }^{2}$ Institute for Sustainable Plant \\ Protection, National Research Council, Strada delle Cacce 73, 10135 Torino, Italy; ${ }^{3}$ Dipartimento di Scienze Agrarie, Forestali e \\ Alimentari, Università di Torino, Largo Paolo Braccini 2, 10095 Grugliasco, TO, Italy; ${ }^{4}$ Division of Viticulture and Pomology, \\ Department of Crop Sciences, University of Natural Resources and Life Sciences, Konrad Lorenz Straße 24, A-3430 Tulln, Vienna, \\ Austria; ${ }^{5}$ Department of Botany, University of Innsbruck, Sternwartestraße 15, 6020 Innsbruck, Austria; ${ }^{6}$ Elettra Sincrotrone Trieste, \\ Area Science Park, 34149 Basovizza, Trieste, Italy; ${ }^{7}$ Institute for Diagnostic and Interventional Radiology, University Medical Center \\ Göttingen, Robert-Koch-Straße 40, 37075 Göttingen, Germany; ${ }^{8}$ Max-Plank-Institute for Experimental Medicine, Hermann-Rein- \\ Straße 3, 37075 Göttingen, Germany; ${ }^{9}$ Department of Plant Sciences, University of California Davis, One Shields Ave, Davis, CA \\ 95616, USA
}

New Phytologist (2018)

doi: $10.1111 / \mathrm{nph} .15368$

Key words: cell membrane, hydraulic recovery, microCT, RNA, X-ray damage, xylem embolism.

\section{Summary}

- Synchrotron X-ray computed micro-tomography (microCT) has emerged as a promising noninvasive technique for in vivo monitoring of xylem function, including embolism build-up under drought and hydraulic recovery following re-irrigation. Yet, the possible harmful effects of ionizing radiation on plant tissues have never been quantified.

- We specifically investigated the eventual damage suffered by stem living cells of three different species exposed to repeated microCT scans. Stem samples exposed to one, two or three scans were used to measure cell membrane and RNA integrity, and compared to controls never exposed to $\mathrm{X}$-rays.

- Samples exposed to microCT scans suffered serious alterations to cell membranes, as revealed by marked increase in relative electrolyte leakage, and also underwent severe damage to RNA integrity. The negative effects of X-rays were apparent in all species tested, but the magnitude of damage and the minimum number of scans inducing negative effects were species-specific.

- Our data show that multiple microCT scans lead to disruption of fundamental cellular functions and processes. Hence, microCT investigation of phenomena that depend on physiological activity of living cells may produce erroneous results and lead to incorrect conclusions.

\section{Introduction}

In plants, long-distance water transport relies on transmission of transpiration-induced negative pressure (= tension) via the xylem conduits connecting root tips to leaf cells (Jensen et al., 2016). Such a fascinating mechanism has the important drawback to be metastable and vulnerable to liquid-to-vapour transition, leading to the blockage of water transport (Zimmermann, 1983). Most frequently, this happens when air is aspirated through interconduit pit membranes into water-filled conduits experiencing critical tensions (Shen et al., 2015; Zwieniecki \& Secchi, 2015). Increased frequency of drought and heat waves is accelerating plant mortality rates worldwide (Hember et al., 2017), and hydraulic failure has emerged as the main cause (Anderegg et al., 2011). A detailed knowledge of species-specific vulnerability to xylem embolism (Maherali et al., 2004) and of the eventual capacity for hydraulic 
recovery (Mayr et al., 2014; Secchi et al., 2017; Klein et al., 2018) is crucial to improve projections of forest and crop resistance/ resilience under future climate scenarios.

Techniques used to measure plant hydraulic conductance upon drought and recovery are generally destructive (Cochard et al., 2013). Stems, roots, petioles and even leaves are excised from plants during or after drought stress and connected to hydraulic systems to measure flow rates across samples under known pressure differences (Sperry et al., 1988). Alternatively, tissues can be infiltrated with dyes to distinguish functioning vs embolized or otherwise nonconducting conduits (Ewers \& Fisher, 1989). Due to negative pressure in functional xylem conduits, samples' excision might cause air entry in the xylem, producing artefactual embolism (Wheeler et al., 2013). The magnitude of this artefact may depend on xylem pressure at sampling time and on conduit length (Beikircher \& Mayr, 2016). Although several studies found no striking evidence for artefacts associated with classical hydraulic techniques (Jacobsen \& Pratt, 2012; Trifilò et al., 2014; Fukuda et al., 2015; Hacke et al., 2015; Scoffoni \& Sack, 2015; Venturas et al., 2015; Ogasa et al., 2016; Nardini et al., 2017; Nolf et al., 2017), it is conceivable that estimates of xylem vulnerability to embolism and restoration of xylem functionality via conduit refilling (Nardini et al., 2018) are biased by destructive sampling protocols.

These controversies have contributed to a move forward in the field of plant hydraulics (Jansen et al., 2015; Venturas et al., 2017) and stimulated the use of nondestructive techniques for in vivo monitoring of xylem function, like magnetic resonance imaging (Zwieniecki et al., 2013), X-ray computed micro-tomography (microCT; Brodersen et al., 2010), and the optical method applied to leaf venation (Brodribb et al., 2016). In particular, microCT has emerged as a very promising technology, due to relatively ease of use, high spatial and temporal resolution, good contrast between air-filled and water-filled spaces, and fast scan times (Dhondt et al., 2010; Pajor et al., 2013; Cochard et al., 2015). Due to its supposed noninvasive nature, microCT has been suggested to represent a reference technique to determine xylem vulnerability to embolism (Cochard et al., 2015), and the eventual refilling of embolized conduits which supposedly relies on the activity of living xylem parenchyma cells (Tyree etal., 1999; Brodersen \& McElrone, 2013; Secchi et al., 2017; Nardini et al., 2018). While some studies demonstrated the occurrence of conduit refilling (Brodersen et al., 2010, 2018), others failed to detect hydraulic recovery following drought and re-irrigation (Choat et al., 2015; Knipfer et al., 2015; Charrier et al., 2016; Hochberg et al., 2016).

These contrasting findings raise questions about possible factors affecting the reliability of microCT observations (Pratt \& Jacobsen, 2018). An obvious but often overlooked drawback of microCT is the use of $\mathrm{X}$-ray sources and the potential tissue damage caused by the ionizing radiation (Han \& Yu, 2009; Daly, 2012). Although this has been considered a minor issue because of short scan times, some studies on animal organisms indicated irreversible cellular damage even by exposure to very low X-ray doses (Rothkamm \& Löbrich, 2003; Nguyen et al., 2015). However, respective X-rays effects on plant samples have never been investigated in detail, although previous studies indicated damage of plant tissues after
microCT scans. As an example, Charrier et al. (2016) used vital staining to assess the functional status of stem parenchyma cells after exposure to X-rays, showing that several cells were damaged. Similarly, Savi et al. (2017) reported shrinkage and brownish scar formation in sunflower stems exposed to X-rays. Hence, it is very important and urgent to test eventual negative or otherwise undesired effects of X-rays on the observed samples, considering the raising importance of microCT as a tool for studies on plant hydraulic functioning. Here, we discuss the results from an experiment specifically designed to assess eventual damage to stem living cells during repeated microCT scans.

\section{Materials and Methods}

\section{Plant material}

Experiments were performed on three species: Helianthus annuus, Coffea arabica cv Pacamara and Populus tremula $\times$ alba. Helianthus annuus plants were 6-wk old, with a height of c. $20 \mathrm{~cm}$ and a stem diameter of $2-3 \mathrm{~mm}$ at root collar. Coffea arabica plants were part of a collection of coffee cultivars hosted by the University of Trieste. Experimental plants were 3-yr-old, with a height of 20 to $30 \mathrm{~cm}$, and a stem diameter of 3 to $4 \mathrm{~mm}$. Plants of $P$. tremula $\times$ alba were 3 months old, c. $50 \mathrm{~cm}$ tall with a stem diameter of 3 to $4 \mathrm{~mm}$.

All plants were maintained in a glasshouse at the University of Trieste for $4 \mathrm{wk}$ before experiments (end of September 2017), and regularly watered. Air temperature and relative humidity averaged $16.5^{\circ} \mathrm{C}$ and $60 \%$, respectively. Mean daily photosynthetic photon flux density (PPFD) was $150 \mu \mathrm{mol} \mathrm{m}^{-2} \mathrm{~s}^{-1}$ (maximum $400 \mu \mathrm{mol}$ $\left.\mathrm{m}^{-2} \mathrm{~s}^{-1}\right)$.

\section{Experimental setup}

Experiments were performed at the SYRMEP beamline, Elettra Sincrotrone Trieste (www.elettra.trieste.it). Two silicon filters $(0.5 \mathrm{~mm}$ each) were used to obtain an average $\mathrm{X}$-ray source energy of $25 \mathrm{keV}$, resulting in an entrance dose rate in water of $47 \mathrm{mGy} \mathrm{s}^{-1}$. X-ray window was $4 \mathrm{~mm}$ in height with horizontal opening up to $120 \mathrm{~mm}$. Initial experiments were performed on intact plants of $H$. annuus and $P$. tremula $\times$ alba $(n=3)$ to test for eventual over-heating of stems as a possible factor inducing damage during scans. A type $\mathrm{T}$ thermocouple connected to a datalogger (1000 Series Squirrel, Eltek) was inserted in the stem at half height. The plant was placed on the sample holder and the stem was aligned with the beam. The beam was turned off to allow temperature equilibration for $5 \mathrm{~min}$. Then, the stem was irradiated for $10 \mathrm{~min}$ at a position located $8 \mathrm{~mm}$ above the thermocouple insertion point, while temperature was continuously recorded. After a $5 \mathrm{~min}$ interval without beam, the stage was moved upward and the stem was irradiated $3 \mathrm{~mm}$ above the thermocouple, for another $10 \mathrm{~min}$. The procedure was repeated by directly irradiating the thermocouple insertion point.

The cellular damage caused by microCT scans was assessed by measuring cell membrane integrity estimated by relative electrolyte leakage (REL), and level of RNA degradation on irradiated stem 
tissues. Stem segments with a length of $1 \mathrm{~cm}(n=5)$ were obtained from the mid portion of stems of well-hydrated plants and immediately wrapped in Parafilm ${ }^{\circledR}$ in groups of five (sampled from five different plants). This allowed to prevent desiccation during storage (see later) and to irradiate more samples during each scan. For each species, 14 sample sets (each with five stem pieces) were prepared (total of 70 stem samples per species).

Samples were subjected to microCT scans while horizontally oriented to assure that all cells were exposed to X-rays during the $360^{\circ}$ rotation (the position was checked via real-time visualization). The exposure time was set at $100 \mathrm{~ms}$, at an angular step of $2^{\circ} \mathrm{s}^{-1}$ resulting in $3 \mathrm{~min}$ scan. Samples were then used to measure REL (seven sets) and RNA quality (seven sets), according to experimental design presented in Fig. 1. Exposed samples were tested after one, two or three consecutive scans at 90-min intervals (E1, E2 and E3). Controls (C0, C1, C2, C3) were never exposed to irradiation. Time of exposure and beam energy level were similar to previously reported experiments (e.g. Charrier et al., 2016), although not all experiments are provided with energy level parameter.

The integrity of cell membranes was estimated via REL measurements. $\mathrm{C}$ or $\mathrm{E}$ samples were placed in $1.5 \mathrm{ml}$ vials (one segment per vial) with $1 \mathrm{ml}$ of deionized water. In the case of $C$. arabica and $P$. tremula $\times$ alba, segments were split longitudinally immediately before immersion to favour contact between stem cells and the solution, as preliminary experiments showed that the bark delayed solute diffusion. The tubes were shaken for $30 \mathrm{~min}$ at laboratory temperature. The initial electrical conductivity $\left(C_{\mathrm{i}}\right)$ of the solution was measured (Twin Cond B-173; Horiba, Kyoto, Japan) using a $10 \mu \mathrm{l}$ aliquot. Samples were then subjected to three freezing-thawing cycles $(1 \mathrm{~min}$ in liquid nitrogen followed by $30 \mathrm{~min}$ at laboratory temperature), shaken for $5 \mathrm{~min}$, and the final electrical conductivity was measured $\left(C_{\mathrm{f}}\right)$ on another $10 \mu \mathrm{l}$ aliquot. REL was finally calculated as $\left(C_{\mathrm{i}} l\right.$ $\left.C_{\mathrm{f}}\right) \times 100($ Savi et al., 2016).

For RNA analysis, frozen stems for each species and treatment were pooled and ground in sterile mortars using liquid nitrogen followed by tissue lysing (TissueLyser II; Qiagen, Hilden,
Germany). Total RNA was extracted following Chang etal. (1993), and RNA quantity and quality were determined spectrophotometrically by NanoDrop (Thermo Fisher Scientific, Waltham, MA). RNA integrity (expressed as RNA integrity number, RIN; Schroeder et al., 2006) was finally inspected using the RNA 6000 Nano kit and the Agilent 2100 Bioanalyser (Agilent Technologies, Santa Clara, CA), according to manufacturer's instructions. The RNA integrity number (RIN) is a standard reference for RNA quality assessment, specifically introduced in routine RNA quality control processes to avoid subjective interpretation of results. The RIN values resulting at the end of each Bionalyser run provide a classification of total RNA quality, based on a numbering system ranging from 1 (poor quality and high level of degradation) to 10 (high quality and high integrity levels). As RNA degradation proceeds, there is a decrease in the $18 \mathrm{~S}$ to $28 \mathrm{~S}$ ribosomal RNA band ratio and an increase in the background noise between the 18 and 28 ribosomal peaks (see https://www.agilent.com/cs/library/appli cations/5989-1165EN.pdf).

\section{Statistical analysis}

One-way parametric analysis of variance (ANOVA) was run separately for each species to test differences between REL values measured in $\mathrm{C}$ and $\mathrm{E}$ samples through 'aov' function in 'STATS' package for $\mathrm{R}$ software. Data were $\log$ transformed to meet assumptions of normality and homoscedasticity of variance. Post hoc Tukey's Honestly Significant Differences comparisons were run through 'TukeyHSD' function in 'STATS' package for R.

\section{Results}

Exposing stems of $H$. annuus or $P$. tremula $\times$ alba to X-rays did not result in biologically significant changes in tissue temperature (Fig. 2). Stem temperature oscillated between 25 and $26^{\circ} \mathrm{C}$ with no beam, and no change was detected at a distance of 3 or $8 \mathrm{~mm}$ from the irradiated point even under prolonged exposure $(10 \mathrm{~min})$.

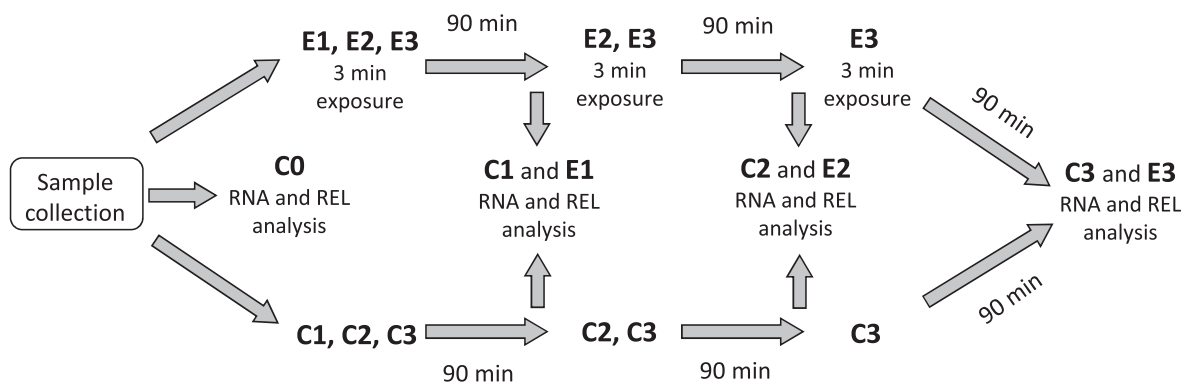

Fig. 1 Experiment time line. C0, control samples (1) immediately used for relative electrolyte leakage (REL) measurements or (2) frozen in liquid nitrogen and kept at $-80^{\circ} \mathrm{C}$ until RNA analysis. $\mathrm{C} 1$, samples excised from stems and stored at laboratory temperature until segments from group E1 were ready, then processed for REL or RNA analyses (see earlier). Samples C1, C2 and C3 were prepared to check eventual time-related trends in cellular damage not associated to X-ray exposure. E1, samples exposed to a single 3-min microCT scan (see later), maintained for 90 min at laboratory temperature to allow eventual damage build-up, then processed for REL or RNA analyses. C2, samples excised from stems and stored at laboratory temperature until samples from group E2 were ready, then processed for REL or RNA measurements. E2, samples exposed to two successive microCT scans (90 min between each exposure and after the last one), then processed for REL or RNA measurements. C3, samples excised from stems and stored at laboratory temperature until samples from group E3 were ready, then processed for REL or RNA measurements. E3, samples exposed to three successive microCT scans (90 min between each exposure and after the last one), then processed for REL or RNA measurements. 
Temperature in stem section directly exposed to radiation rose by $c$. $1^{\circ} \mathrm{C}$ in both tested species.

Cell membrane integrity, quantified via REL measurements, was affected by X-ray exposure in analysed species (Fig. 3). In all plants, REL of C0 samples was c. $25 \%$, and this value did not change significantly as a function of time from excision in C1, C2 and C3 samples (Fig. 3). In the case of H. annuus, the first scan did not induce changes in REL, however, these became apparent in E2 and E3, when REL peaked to $70 \%$, with some samples reaching values as high as $90 \%$. In P. tremula $\times$ alba, REL increased to $35 \%$ in E2 and remained similar in E3. In C. arabica, an increase of REL to $45 \%$ (albeit not significant due to large data variability) was already observed in E1 samples, reaching values $>50 \%$ in E3.

Total RNA quality was estimated by the RIN value, as this is a reliable proxy to compare the integrity of RNA in different samples. Analyses based on this metric confirmed the results obtained by REL measurements, showing similar variability and resistance of species to radiation (Fig. 4). In the case of $H$. annuus, the first scan did not affect RNA quality (E1, RIN 7.5). However, RNA degradation increased after the second exposure, and the RNA after the third exposure (E3) was almost fully degraded (Fig. 4). In this species, the controls $(\mathrm{C} 0-\mathrm{C} 3)$ showed no degradation of RNA quality. There was no effect of time or X-ray exposures on RNA

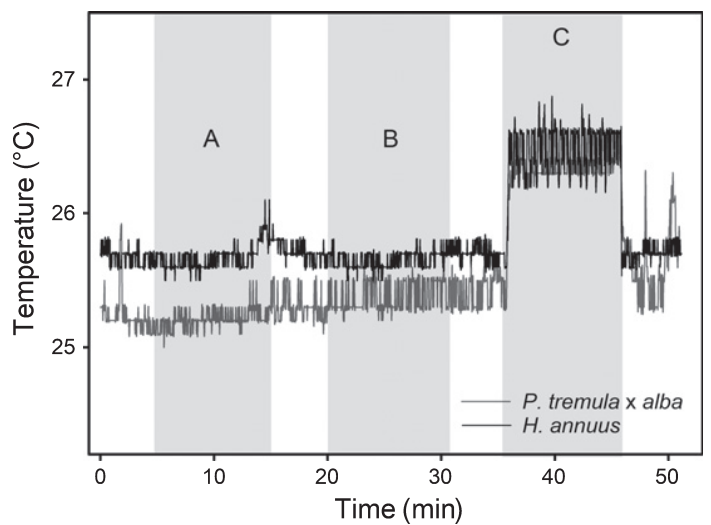

Fig. 2 Temperature changes over time in irradiated stems of Populus tremula $\times$ alba (grey line) and Helianthus annuus (black line) at $8 \mathrm{~mm}(\mathrm{~A})$, $3 \mathrm{~mm}$ (B) and at the same position (C) of irradiation point. quality of samples collected from $P$. tremula $\times$ alba stems, although E3 samples had slightly lower RNA quality (RIN 6.2; Fig. 4). After one scan, RNA extracted from C. arabica was partially degraded (E1; RIN 4.1), in comparison with controls (C1, RIN 7). However, both X-ray exposures and time from excision influenced the RNA quality in this species (see C2-C3 and E2-E3; Fig. 4) confirming that $C$. arabica was sensitive to both manipulation and X-rays.

\section{Discussion}

$\mathrm{X}$-Ray microCT is emerging as an important new tool for the visualization and quantification of xylem embolism (Cochard et al., 2015). Based on its supposed noninvasive nature, microCT has also been used to visualize eventual post-drought recovery. In both cases, plants are generally exposed to successive microCT scans to check embolism build-up during plant dehydration (Choat et al., 2016), or conduit refilling following re-watering (Charrier et al., 2016).

Xylem conduits are frequently considered as inert pipelines, but long-distance water transport relies on the activity of phloem and parenchyma, for example for the regulation of xylem sap ionic content (Zwieniecki et al., 2001; Nardini et al., 2011), modulation of xylem sap surface tension (Losso et al., 2017), release of sugars and water during the refilling of embolized conduits (Secchi et al., 2017) and production of conduit-filling exudates as a response to wounds (Jacobsen etal., 2018). Hence, any eventual damage to living cells can be suspected to alter xylem function, thus casting doubts on the reliability of techniques inducing harmful effects on phloem or parenchyma. Our data clearly show that microCT scans produce severe cellular damage and call for renewed caution in the interpretation of findings based on this technique (Pratt \& Jacobsen, 2018). The X-ray energy level and scan times in our experiment were similar to or even lower than those used in several recent studies (e.g. Charrier et al., 2016; Choat et al., 2016; Knipfer et al., 2017). Yet, the X-ray dose was high enough to induce damage to both cell membranes and RNA.

Samples exposed to microCT scans showed significant increases in REL, indicating serious alterations to cell membranes. This is not surprising, as several studies have shown that X-rays produce

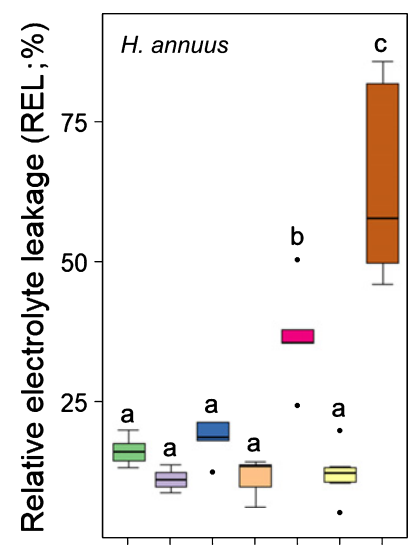

C0 C1 E1 C2 E2 C3 E3

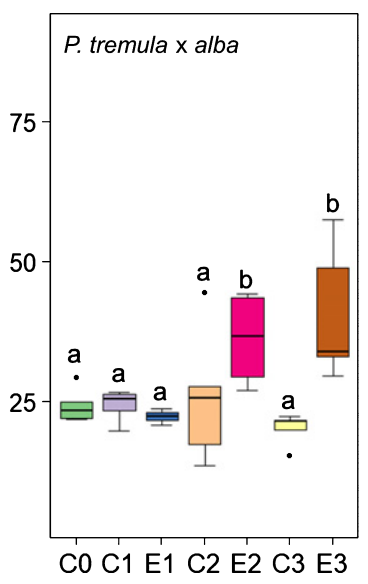

C0 C1 E1 C2 E2 C3 E3

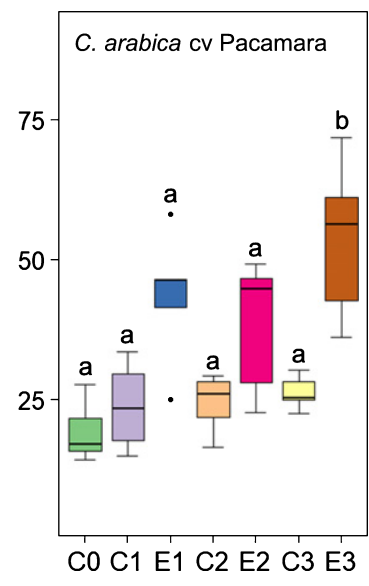

Fig. 3 Median values, 25th and 75th percentiles of relative electrolyte leakage (REL) in control (C) and exposed (E) sample groups in Helianthus annuus, Populus tremula $\times$ alba and in Coffea arabica cv Pacamara. Different letters indicate statistically significant differences among groups $(P<0.05)$. 
irreversible damage to membrane lipid bilayers due to phase transformation and lamellar stacking (Köteles, 1982; Cheng \& Caffrey, 1996; Cherezov et al., 2002), with consequent effects on membrane permeability (Cao et al., 2015). Cherezov et al. (2002) reported that membrane damage is not associated to temperature effects during sample irradiation at synchrotron light sources, as also confirmed by the lack of over-heating recorded in our samples, but it rather depends on generation of free radicals. Most importantly, Cherezov et al. (2002) evidenced that the damage was independent on the source energy in a $9-17 \mathrm{keV}$ range, suggesting that the risk of membrane damage is intrinsic to the technique and cannot be reduced by modifying X-ray energy level without losing image quality and resolution.

In addition to disruption of cell membranes, our data indicate that microCT scans negatively affect RNA quality. This is also not unexpected, as ionizing radiation is known to induce significant alterations on nucleic acids, often resulting in DNA double-strand breaks (Rothkamm \& Löbrich, 2003; Han \& Yu, 2009) and reactive oxygen species (ROS)-mediated DNA/RNA disruption (Van Huystee et al., 1968; Tominaga et al., 2004), finally leading to severe RNA and/or protein damage (Daly, 2012). Our data from plants are in line with findings obtained on animal cell models and suggest that, as a consequence of RNA damage, protein synthesis can be impaired in stem parenchyma cells after microCT scans.

Both membrane damage and RNA degradation were observed in three studied species, but the susceptibility to X-ray damage was species-specific. Coffea arabica was damaged by a single scan, while two-to-three scans were necessary to produce significant effects in the other two species. It is possible that not all microCT experiments performed on different species and reported in the literature are affected to the same extent by harmful radiation effects, potentially explaining the observed range of hydraulic recovery in different species (Choat et al., 2015; Knipfer et al., 2015; Charrier et al., 2016; Brodersen et al., 2018). Our findings call for a careful reassessment of previous conclusions, based on dedicated experiments to evaluate the susceptibility of individual species to the specific experimental conditions adopted.

Our data show that multiple microCT scans lead to disruption of fundamental cellular functions and processes. Hence, microCT investigation of phenomena that depend on physiological activity of living cells may produce erroneous results and lead to incorrect conclusions. This probably applies to conduit refilling, which has been suggested to occur via secretion of sugars into embolized conduits by phloem and vessel-associated parenchyma cells to generate the osmotic forces necessary to counterbalance eventual residual tension in still functioning elements (Secchi \& Zwieniecki, 2012). Such a mechanism requires the activation of genes encoding key proteins involved in carbohydrate metabolism pathways and membrane transport of inorganic ions, sugar molecules and water (Secchi etal., 2011; Perrone etal., 2012; Chitarra et al., 2014; Secchi \& Zwieniecki, 2016). Thus, failure in detecting conduit refilling in microCT experiments, when involving repeated scans of the same plant subjected to drought stress and then re-irrigated (Choat etal., 2015; Knipfer etal., 2015, 2017; Charrier etal., 2016), might arise from X-ray induced damage to living cells. We
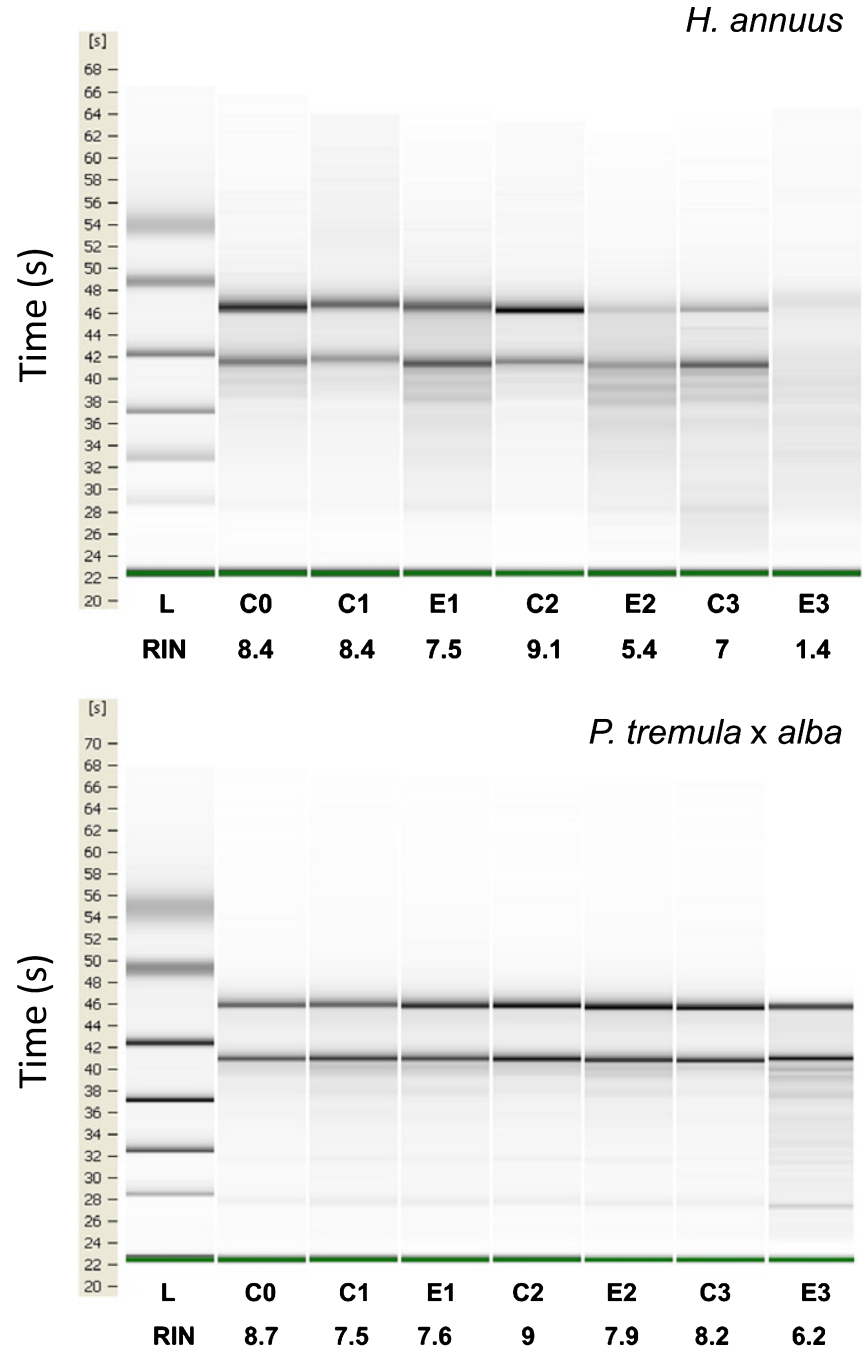

C. arabica cv Pacamara

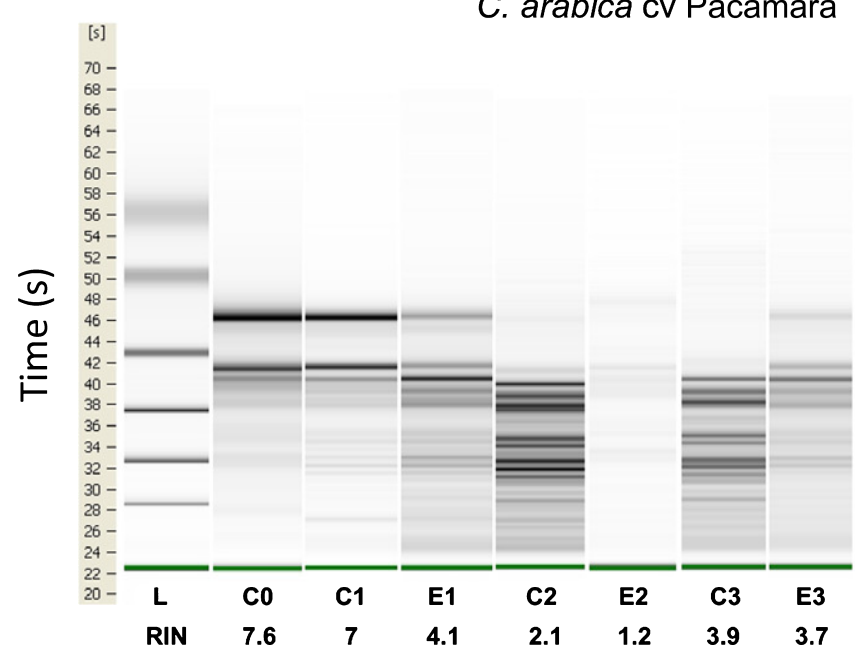

Fig. 4 Evaluation of RNA integrity by Bioanalyser assay. For each RNA sample, extracted from control (C) or exposed (E) plant stems (Helianthus annuus, Populus tremula $\times$ alba and Coffea arabica cv Pacamara), the related RIN (RNA integrity number) is provided below each lane of the gel. L, ladder. 
strongly suggest that such evidence should be re-evaluated in the light of our findings and also recommend that xylem vulnerability or recovery curves generated by microCT should be based on sets of different plants, so that a single plant at any given water status or physiological stage is scanned and observed only once if the species is susceptible to applied radiation levels. This approach might raise doubts on the advantages of microCT as an alternative or complementary technique with respect to classical hydraulic measurements. However, we believe that microCT is very important to provide information or confirmation on the functional status of conduits with no risk of bias due to cutting procedures, and with a three-dimensional (3D) resolution which could not be obtained with hydraulic techniques.

MicroCT observations are increasingly used to observe xylem embolism build-up during plant dehydration. It is assumed that embolism spreads by aspiration of air through the pores of pit membranes. Thus, the validity of observations of embolism spread is seemingly not challenged by our findings, unless X-rays disrupt and alter the structure and porosity of pit membranes, leading to erroneous estimates of embolism vulnerability. Also, damage to living cells might result in wound responses leading to rapid filling of xylem conduits with gels (Crews et al., 2003; Soukup \& Votrubová, 2005; Marañón-Jiménez et al., 2017; Che-Husin et al., 2018; Jacobsen etal., 2018). Such an effect would cause conduits to appear filled with a liquid phase even though nonconducting (Pratt \& Jacobsen, 2018), leading to overestimate plant resistance to xylem embolism. The occurrence and relevance of these effects should be evaluated by future studies.

\section{Acknowledgements}

This study was made possible by Elettra Sincrotrone Trieste, which allowed and funded access to the SYRMEP beamline (proposals no. 20165201 and no. 20165277). The authors thank Birgit Dämon (University of Innsbruck) for assistance during experiments at SYRMEP.

\section{Author contributions}

A.N., F.S., M.A.Z. and S.M. planned and designed the research. F.P., C.P., T.S., A.L., S.C., G.T., C.D., A.B., A.G., A.M., S.M., M.A.Z., A.N. and F.S. contributed to perform experiments and analyse data. F.P., A.N. and F.S. wrote the manuscript, with contribution and revision by all other authors.

\section{References}

Anderegg WRL, Berry JA, Smith DD, Sperry JS, Anderegg LDL, Field CB. 2011. The roles of hydraulic and carbon stress in a widespread climate-induced forest die-off. Proceedings of the National Academy of Sciences, USA 109: 233-237.

Beikircher B, Mayr S. 2016. Avoidance of harvesting and sampling artefacts in hydraulic analyses: a protocol tested on Malus domestica. Tree Physiology 36: 797-803.

Brodersen CR, Knipfer T, McElrone AJ. 2018. In vivo visualization of the final stages of xylem vessel refilling in grapevine (Vitis vinifera) stems. New Phytologist 217: $117-126$
Brodersen CR, McElrone AJ. 2013. Maintenance of xylem network transport capacity: a review of embolism repair in vascular plants. Frontiers in Plant Science 4: 108.

Brodersen CR, McElrone AJ, Choat B, Matthews MA, Shackel KA. 2010. The dynamics of embolism repair in xylem: in vivo visualizations using high-resolution computed tomography. Plant Physiology 154: 1088-1095.

Brodribb TJ, Skelton RP, McAdam SAM, Bienaimé D, Lucani CJ, Marmottant P. 2016. Visual quantification of embolism reveals leaf vulnerability to hydraulic failure. New Phytologist 209: 1403-1409.

Cao G, Zhang M, Miao J, Li W, Wang J, Lu D, Xia J. 2015. Effects of Xray and carbon ion beam irradiation on membrane permeability and integrity in Saccharomyces cerevisiae cells. Journal of Radiation Research 56: 294 304.

Chang S, Puryear J, Cairney J. 1993. A simple and efficient method for isolating RNA from pine tree. Plant Molecular Biology Report 11: 113-116.

Charrier G, Torres-Ruiz JM, Badel E, Burlett R, Choat B, Cochard H, Delmas CEL, Domec JC, Jansen S, King A et al. 2016. Evidence for hydraulic vulnerability segmentation and lack of xylem refilling under tension. Plant Physiology 172: 1657-1668.

Che-Husin NM, Joyce DC, Irving DE. 2018. Gel xylem occlusions decrease hydraulic conductance of cut Acacia holosericea foliage stems. Postharvest Biology and Technology 135: 27-37.

Cheng A, Caffrey M. 1996. Free radical mediated X-ray damage of model membranes. Biophysical Journal 70: 2212-2222.

Cherezov V, Riedl KM, Caffrey M. 2002. Too hot to handle? Synchrotron X-ray damage of lipid membranes and mesophases. Journal of Synchrotron Radiation 9 333-341.

Chitarra W, Balestrini R, Vitali M, Pagliarani C, Perrone I, Schubert A, Lovisolo C. 2014. Gene expression in vessel-associated cells upon xylem embolism repair in Vitis vinifera L. petioles. Planta 239: 887-899.

Choat B, Badel E, Burlett R, Delzon S, Cochard H, Jansen S. 2016. Noninvasive measurement of vulnerability to drought-induced embolism by X-ray microtomography. Plant Physiology 170: 273-282.

Choat B, Brodersen CR, McElrone AJ. 2015. Synchrotron X-ray microtomography of xylem embolism in Sequoia sempervirens saplings during cycles of drought and recovery. New Phytologist 205: 1095-1105.

Cochard H, Badel E, Herbette S, Delzon S, Choat B, Jansen S. 2013. Methods for measuring plant vulnerability to cavitation: a critical review. Journal of Experimental Botany 64: 4779-4791.

Cochard H, Delzon S, Badel E. 2015. X-ray microtomography (microCT): a reference technology for high-resolution quantification of xylem embolism in trees. Plant, Cell \& Environment 38: 201-206.

Crews LJ, McCully ME, Canny MJ. 2003. Mucilage production by wounded xylem tissue of maize roots - time course and stimulus. Functional Plant Biology 30: 755 766.

Daly MJ. 2012. Death by protein damage in irradiated cells. DNA Repair 11: 12-21 Dhondt S, Vanhaeren H, Van Loo D, Cnudde V, Inzé D. 2010. Plant structure visualization by high-resolution X-ray computed tomography. Trends in Plant Science 15: 419-422.

Ewers FW, Fisher JB. 1989. Techniques for measuring vessel lengths and diameters in stems of woody plants. American Journal of Botany 76 : 645-656.

Fukuda K, Kawaguchi D, Aihara T, Ogasa MY, Miki NH, Haishi T, Umebayashi T. 2015. Vulnerability to cavitation differs between current-year and older xylem: non-destructive observation with a compact magnetic resonance imaging system of two deciduous diffuse-porous species. Plant, Cell \& Environment 38: 25082518.

Hacke UG, Venturas MD, MacKinnon ED, Jacobsen AL, Sperry JS, Pratt RB. 2015. The standard centrifuge method accurately measures vulnerability curves of long-vesselled olive stems. New Phytologist 205: 116-127.

Han W, Yu KN. 2009. Response of cells to ionizing radiation. In: Tjong SC, ed. Advances in biomedical sciences and engineering. United Arab Emirates: Bentham Science Publisher Ltd, 204-262.

Hember RA, Kurz WA, Coops NC. 2017. Relationships between individual-tree mortality and water-balance variables indicate positive trends in water stressinduced tree mortality across North America. Global Change Biology 23: 16911710 . 
Hochberg U, Herrera JC, Cochard H, Badel E. 2016. Short-time xylem relaxation results in reliable quantification of embolism in grapevine petioles and sheds new light on their hydraulic strategy. Tree Physiology 36: 748-755.

Jacobsen AL, Pratt RB. 2012. No evidence for an open vessel effect in centrifugebased vulnerability curves of a long-vesselled liana (Vitis vinifera). New Phytologist 194: 982-990.

Jacobsen AL, Valdovinos-Ayala J, Pratt RB. 2018. Functional lifespans of xylem vessels: development, hydraulic function, and post-function of vessels in several species of woody plants. American Journal of Botany 105: 142-150.

Jansen S, Schuldt B, Choat B. 2015. Current controversies and challenges in applying plant hydraulic techniques. New Phytologist 205: 961-964.

Jensen KH, Berg-Sørensen K, Bruus H, Holbrook NM, Liesche J, Schulz A, Zwieniecki MA, Bohr T. 2016. Sap flow and sugar transport in plants. Reviews of Modern Physics 88: 035007.

Klein T, Zeppel MJB, Anderegg WRL, Bloemen J, De Kauwe MG, Hudson P, Ruehr NK, Powell TL, von Arx G, Nardini A. 2018. Xylem embolism refilling and resilience against drought-induced mortality in woody plants: processes and trade-offs. Ecological Research. doi: 10.1007/s11284-018-1588-y.

Knipfer T, Brodersen CR, Zedan A, Kluepfel DA, McElrone AJ. 2015. Patterns of drought-induced embolism formation and spread in living walnut saplings visualized using X-ray microtomography. Tree Physiology 35: 744-755.

Knipfer T, Cuneo IF, Earles JM, Reyes C, Brodersen CR, McElrone AJ. 2017. Storage compartments for capillary water rarely refill in an intact woody plant. Plant Physiology 175: 1649-1660.

Köteles GJ. 1982. Radiation effects on cell membranes. Radiation and Environmental Biophysics 21: 1-18.

Losso A, Beikircher B, Dämon B, Kikuta S, Schmid P, Mayr S. 2017. Xylem sap surface tension may be crucial for hydraulic safety. Plant Physiology 175: 11351143 .

Maherali H, Pockman WT, Jackson RB. 2004. Adaptive variation in the vulnerability of woody plants to xylem cavitation. Ecology 85: 2184-2199.

Marañón-Jiménez S, Van den Bulcke J, Piayda A, Van Acker J, Cuntz M, Rebmann C, Steppe K. 2017. X-ray computed microtomography characterizes the wound effect that causes sap flow underestimation by thermal dissipation sensors. Tree Physiology 38: 288-302.

Mayr S, Schmid P, Laur J, Rosner S, Charra-Vaskou K, Dämon B, Hacke UG. 2014. Uptake of water via branches helps timberline conifers refill embolized xylem in late winter. Plant Physiology 164: 1731-1740.

Nardini A, Salleo S, Jansen S. 2011. More than just a vulnerable pipeline: xylem physiology in the light of ion-mediated regulation of plant water transport. Journal of Experimental Botany 62: 4701-4718.

Nardini A, Savi T, Losso A, Petit G, Pacilè S, Tromba G, Mayr S, Trifilò P, Lo Gullo MA, Salleo S. 2017. X-ray microtomography observations of xylem embolism in stems of Laurus nobilis are consistent with hydraulic measurements of percentage loss of conductance. New Phytologist 213: 1068-1075.

Nardini A, Savi T, Trifilò P, Lo Gullo MA. 2018. Drought stress and the recovery from xylem embolism in woody plants. Progress in Botany 79: 197-231.

Nguyen PK, Lee WH, Li YF, Hong WX, Hu S, Chan C, Liang G, Nguyen I, Ong SG, Churko J et al. 2015. Assessment of the radiation effects of cardiac CT angiography using protein and genetic biomarkers. JACC: Cardiovascular Imaging 8: 873-884.

Nolf M, Lopez R, Peters JMR, Flavel RJ, Koloadin LS, Young IM, Choat B. 2017. Visualization of xylem embolism by X-ray microtomography: a direct test against hydraulic measurements. New Phytologist 214: 890-898.

Ogasa MY, Utsumi Y, Miki NH, Yazaki K, Fukuda K. 2016. Cutting stems before relaxing xylem tension induces artefacts in Vitis coignetiae, as evidenced by magnetic resonance imaging. Plant, Cell \& Environment 39: 329-337.

Pajor R, Fleming A, Osborne CP, Rolfe SA, Sturrock CJ, Mooney SJ. 2013. Seeing space: visualization and quantification of plant leaf structure using X-ray microcomputed tomography. Journal of Experimental Botany 64: 385-390.

Perrone I, Pagliarani C, Lovisolo C, Chitarra W, Roman F, Schubert A. 2012. Recovery from water stress affects grape leaf petiole transcriptome. Planta 235: 1383-1396.

Pratt RB, Jacobsen AL. 2018. Identifying which conduits are moving water in woody plants: a new HRCT-based method. Tree Physiology. doi: 10.1093/ treephys/tpy034.
Rothkamm K, Löbrich M. 2003. Evidence for a lack of DNA double-strand break repair in human cells exposed to very low X-ray doses. Proceedings of the National Academy of Sciences, USA 100: 5057-5062.

Savi T, Dal Borgo A, Love VL, Andri S, Tretiach M, Nardini A. 2016. Drought versus heat: what's the major constraint on Mediterranean green roof plants? Science of the Total Environment 566: 753-760.

Savi T, Miotto A, Petruzzellis F, Losso A, Pacilè S, Tromba G, Mayr S, Nardini A. 2017. Drought-induced embolism in stems of sunflower: a comparison of in vivo micro-CT observations and destructive hydraulic measurements. Plant Physiology \& Biochemistry 120: 24-29.

Schroeder A, Mueller O, Stocker S, Salowsky R, Leiber M, Gassmann M, Lightfoot S, Menzel W, Granzow M, Ragg T. 2006. The RIN: an RNA integrity number for assigning integrity values to RNA measurements. BMCMolecular Biology 7: 3 .

Scoffoni C, Sack L. 2015. Are leaves 'freewheelin'? Testing for a Wheeler-type effect in leaf xylem hydraulic decline. Plant, Cell \& Environment 38: 534-543.

Secchi F, Gilbert ME, Zwieniecki MA. 2011. Transcriptome response to embolism formation in stems of Populus trichocarpa provides insight into signaling and the biology of refilling. Plant Physiology 157: 1419-1429.

Secchi F, Pagliarani C, Zwieniecki MA. 2017. The functional role of xylem parenchyma cells and aquaporins during recovery from severe water stress. Plant, Cell \& Environment 40: 858-871.

Secchi F, Zwieniecki MA. 2012. Analysis of xylem sap from functional (nonembolized) and nonfunctional (embolized) vessels of Populus nigra: chemistry of refilling. Plant Physiology 160: 955-964.

Secchi F, Zwieniecki MA. 2016. Accumulation of sugars in the xylem apoplast observed under water stress conditions is controlled by xylem pH. Plant, Cell \& Environment 39: 2350-2360.

Shen F, Cheng Y, Zhang L, Gao R, Shao X. 2015. Experimental study of the types of cavitation by air seeding using light microscopy. Tree Physiology 35: 1325-1332.

Soukup AS, Votrubová O. 2005. Wound-induced vascular occlusions in tissues of the reed Phragmites australis: their development and chemical nature. New Phytologist 167: 415-424.

Sperry JS, Donnelly JR, Tyree MT. 1988. A method for measuring hydraulic conductivity and embolism in xylem. Plant, Cell \& Environment 11: 35-40.

Tominaga H, Kodama S, Matsuda N, Suzuki K, Watanabe M. 2004. Involvement of reactive oxygen species (ROS) in the induction of genetic instability by radiation. Journal of Radiation Research 45: 181-188.

Trifilò P, Raimondo F, Lo Gullo MA, Barbera PM, Salleo S, Nardini A. 2014. Relax and refill: xylem rehydration prior to hydraulic measurements favours embolism repair in stems and generate artificially low PLC values. Plant, Cell \& Environment 37: 2491-2499.

Tyree MT, Salleo S, Nardini A, Lo Gullo MA, Mosca R. 1999. Refilling of embolized vessels in young stems of Laurel. Do we need a new paradigm? Plant Physiology 120: 11-21.

Van Huystee RB, Jachymczyk W, Tester CF, Cherry JH. 1968. X-irradiation effects on protein synthesis and synthesis of messenger ribonucleic acid from peanut cotyledons. Journal of Biological Chemistry 243: 2315-2320.

Venturas MD, MacKinnon ED, Jacobsen AL, Pratt RB. 2015. Excising stem samples underwater at native tension does not induce xylem cavitation. Plant, Cell \& Environment 38: 1060-1068.

Venturas MD, Sperry JS, Hacke UG. 2017. Plant xylem hydraulics: what we understand, current research, and future challenges. Journal of Integrative Plant Biology 59: 356-389.

Wheeler JK, Huggett BA, Tofte AN, Rockwell FE, Holbrook NM. 2013. Cutting xylem under tension or supersaturated with gas can generate PLC and the appearance of rapid recovery from embolism. Plant, Cell \& Environment 36 : $1938-1949$.

Zimmermann MH. 1983. Xylem structure and the ascent of sap. Berlin, Germany: Springer Verlag.

Zwieniecki MA, Melcher PJ, Ahrens ET. 2013. Analysis of spatial and temporal dynamics of xylem refilling in Acer rubrum L. using magnetic resonance imaging. Frontiers in Plant Science 4: 265.

Zwieniecki MA, Melcher PJ, Holbrook NM. 2001. Hydrogel control of xylem hydraulic resistance in plants. Science 291: 1059-1062.

Zwieniecki MA, Secchi F. 2015. Threats to xylem hydraulic function of trees under 'new climate normal' conditions. Plant, Cell \& Environment 38: 1713-1724. 